\title{
O FUNCIONAMENTO DO TEXTO CONSTITUCIONAL À LUZ DA ARTICULAÇÃO DE ORAÇÕES E DAS RELAÇÕES
}

\section{RETÓRICAS ${ }^{1}$}

\author{
Angélica Alves Ruchkys² (UFMG)
}

\section{Introdução}

A análise aqui empreendida busca investigar, sob o enfoque funcionalista, as relações entre orações e porções maiores de texto. Essa investigação se baseia na hipótese de que tais porções se manifestam de uma maneira muito peculiar no gênero lei, uma vez que nele há basicamente dois formatos de redação: a construção de enumerações, expressas em incisos, alíneas, e itens ${ }^{3}$ e a elaboração de afirmações sintaticamente autônomas, expressas em artigos e parágrafos ${ }^{4}$.

Como fundamentação teórica, tomar-se-á o estudo de Halliday (1985) sobre a articulação de orações e o de Mathiessen e Thompson (1988) sobre as relações retóricas. O primeiro, tendo por base o complexo de orações, ou seja, seqüência de orações estruturalmente ligadas, propõe o cruzamento dos eixos tático e lógico-semântico. Assim, dentro da oração complexa, as relações entre as orações são interpretadas em termos funcionais-semânticos. O segundo modelo teórico busca investigar a articulação de orações e de porções textuais maiores a partir da noção de relações retóricas, as quais organizam a coerência do texto nos seus diversos níveis. Segundo os autores do segundo modelo, há basicamente dois tipos de relações que podem ser estabelecidas entre orações ou entre porções maiores de texto: as do tipo núcleo-satélite, em que uma porção é ancilar da outra; e as relações do tipo listagem, em que as porções textuais têm o mesmo estatuto. Nas relações do primeiro tipo, uma porção modifica a outra, havendo entre elas, portanto, uma vinculação por dependência o que não ocorre nas relações do segundo tipo, nas quais cada porção textual possui o mesmo estatuto, constituindo, ambas, núcleos distintos.

Subsidiariamente, a noção de idea unit de Chafe (1980), traduzida por Decat (1993) como unidade informacional, será utilizada na identificação de porções textuais tanto em períodos

\footnotetext{
${ }^{1}$ Agradeço ao Centro Universitário de Belo Horizonte o apoio à minha participação neste Congresso. 2 angelicaruchkys@yahoo.com.br

3 O incisos são grafados por algarismos romanos seguidos de travessão [ I — , II — , III — etc....]. As alíneas são desdobramentos dos incisos e são indicadas pelas letras do alfabeto em minúsculo e itálico, seguidas de parêntese $[a), b) c$ ) etc...] Os itens são desdobramentos das alíneas e são grafados por algarismo arábicos ["1", "2" etc.].

${ }^{4}$ Os parágrafos do texto legislativo são também denominados incisos.
} 
constituídos de uma única oração quanto em períodos compostos, constituídos de duas ou mais orações. Estes últimos referem-se especialmente àqueles em que uma das orações têm o verbo não-explícito em sua estrutura, mas deduzível do complexo oracional como um todo. Segundo Chafe citado por Decat $(1993,113)$, as unidades informacionais

[...] possuem [...] por volta de sete palavras e podem ser identificadas pela entonação (contorno entonacional de final de cláusula), pela pausa (ou hesitação), ainda que breve, que as separa de outra unidade. Além disso, as unidades informacionais tendem a se caracterizar sintaticamente como constituindo uma única cláusula. Esses três fatores não têm, necessariamente, de estar todos presentes na identificação da unidade informacional.

No que se refere à metodologia já existente aplicada à elaboração das leis, será considerado o fato de que a técnica legislativa prescreve, entre outros aspectos, não só as partes em que se podem subdividir tais textos como também o tipo de conteúdo próprio a cada um de seus elementos constituintes.

O presente artigo $^{5}$ propõe uma investigação lingüística da parte inicial da Constituição da República Federativa do Brasil $^{6}$ — lei a que estão submetidos os demais códigos do ordenamento jurídico. Trata-se do Capítulo I, DOS DIREITOS E DEVERES INDIVIDUAIS , do Título II, DOS DIREITOS E GARANTLAS FUNDAMENTAIS'.

No texto constitucional, encontram-se artigos, parágrafos, incisos, alíneas. A dinâmica de entrelaçamento desses elementos se dá hierarquicamente. Conforme Carvalho (2003, 57), os "artigos se subdividem em parágrafos ou em incisos, estes em alíneas que se desdobrarão em itens. De maneira inversa, eles se agrupam em Seção, Capítulo, Título, Livro, Parte [...]”. Mais adiante, o autor define o artigo como sendo "o elemento central tanto para a subdivisão do texto legislativo como para o seu agrupamento". O agrupamento máximo a que chega o texto constitucional é o de capítulos que formam o Título. Há nove Títulos na Constituição de 1988.

O artigo é, portanto, a unidade básica do texto legal. Nele, apresenta-se uma disposição ou princípio, a que se subordinam parágrafos, incisos, alíneas e itens. O parágrafo, por sua vez, é a primeira divisão de um artigo e deve ocorrer toda vez que se faz necessário restringir ou explicar detalhadamente o comando apresentado no artigo. Segundo Pinheiro, citado por Carvalho $(2003,62)$, as regras para a redação de parágrafos são as seguintes:

$1^{\text {a }}$ regra - Constitui objeto do parágrafo o conjunto de pormenores ou preceitos necessários à perfeita inteligência do artigo.

\footnotetext{
${ }^{5}$ Este artigo faz parte de uma pesquisa mais abrangente sobre a natureza e o funcionamento da Constituição Federal de 1988, tese de doutorado em andamento no Programa de Pós-Graduação em Estudos Lingüísticos da Faculdade de Letras da UFMG.

${ }^{6}$ As demais referências, neste texto, à Constituição da República Federativa do Brasil, apresentar-se-ão em formato mais "econômico", a saber: "Constituição Federal" ou, simplesmente, "Constituição".

${ }^{7}$ Ver anexo.
} 
2a regra - A matéria no parágrafo deve estar intimamente ligada à de que se ocupa o artigo.

$3^{a}$ regra - O parágrafo deve conter as restrições do artigo ou, então, completar as disposições deste último.

A técnica legislativa prescreve ainda que, caso se apresente um assunto que não possa ser resumido no próprio artigo ou que não se mostre apropriado a compor um parágrafo, abram-se incisos. Como elementos discriminativos do artigo, os incisos apresentam-se na lei sob a forma enumerativa. Outros meios de enumerar detalhes que não se adeqüem no interior de um artigo são as alíneas e, dentro delas, os itens. Carvalho $(2003,62)$ afirma que os "incisos, por serem indicados em algarismos romanos, além de poderem ser usados nas pequenas enumerações, são particularmente úteis para as grandes enumerações, já que as alíneas têm suas possibilidades limitadas". Daí a adoção das alíneas somente para desdobrar os parágrafos ou os incisos, e não os artigos diretamente.

Enquanto os incisos, as alíneas e os itens se prestam à enumeração de detalhes - os artigos e parágrafos, embora relacionados, mantêm entre si uma autonomia sintática aparentemente forte. Os interstícios entre as orações distribuídas entre parágrafos e artigos são subsumidos por esse tipo de formatação. O conteúdo da afirmação colocada no artigo e o conteúdo da afirmação colocada no parágrafo - embora tratem, por definição, do mesmo assunto - apresentam-se apartados e até "fisicamente" distantes na superfície do texto, quando, por exemplo, interpõemse incisos e/ou alíneas entre eles.

Diante dessa estrutura peculiar e tão rigidamente fixada, sobrevem a pergunta: por meio de que estratégias a Constituição — lei maior a que se submetem todos os diplomas legais vigentes $^{8}$ — é tão diversamente interpretada? A lingüística, particularmente a abordagem funcional-discursiva, pode oferecer, senão a resposta, pelo menos os indicativos de como a Constituição Federal se organiza ao nível do texto e, em decorrência disto, proporcionar também subsídios para a interpretação da carta constitucional na instância jurídica.

\subsection{O problema da identificação das orações independentes}

A Constituição, em seu Título II - DOS DIREITOS E GARANTLAS FUNDAMENTAIS -, capítulo I DOS DIREITOS E DEVERES INDIVIDUAIS E COLETIVOS declara a igualdade entre as pessoas e a inviolabilidade deste direito e de outros, também fundamentais: os direitos à vida, à liberdade, à segurança e à propriedade. Em seguida, o texto constitucional explicita em que termos tais direitos devem ser considerados. Após uma lista de 78 incisos, é apresentada, no primeiro parágrafo do artigo, afirmação concernente à

\footnotetext{
${ }^{8}$ Segundo Houaiss $(2001,1047)$, diploma legal é "lei ou corpo de leis em vigor".
} 
operacionalização dos direitos e garantias elencados nos incisos. Os parágrafos $2^{\circ}, 3^{\circ}$ e $4^{\circ}$ referem-se à relação entre o que a carta constitucional brasileira admite como direitos humanos e o que é admitido, neste campo, no âmbito internacional. $O$ parágrafo $3^{\circ}$ mostra a forma de admissão de direitos advindos de legislação internacional à carta constitucional brasileira. $\mathrm{O} 4^{\circ}$ parágrafo acrescenta a informação de que o País se submete à jurisdição do Tribunal Penal Internacional ao qual tenha manifestado adesão.

No Título I — DOS PRINCÍPIOS FUNDAMENTAIS —, encontram-se princípios e fundamentos gerais adotados pelo País, que orientam e vinculam o conteúdo do Título II, cujo capítulo primeiro é objeto do presente estudo.

No interior do Título II, os capítulos II, III, IV e V continuam o detalhamento dos direitos e deveres individuais e coletivos enunciados no primeiro capítulo, distinguindo-os em direitos sociais (Capítulo II), direitos da nacionalidade (Capítulo III), direitos políticos (Capítulo IV) e direitos dos partidos políticos (Capítulo V). No entanto, como foi dito, o presente artigo se aterá ao Capítulo I, no qual o texto constitucional enuncia direitos e deveres individuais e coletivos, sem ainda distinguí-los como o faz nos capítulos posteriores dessa seção (Título II). O quadro seguinte mostra o esquema da macro-estrutura retórica do texto em estudo.

A IGUALDADE FORMAL E A GARANTIA DOS DIREITOS À VIDA, À LIBERDADE, À IGUALDADE, À SEGURANÇA E À PROPRIEDADE.

DESCRIÇÃO/EXPLICITAÇÃO DOS DIREITOS FUNDAMENTAIS OPERACIONALIZAÇÃO DOS DIREITOS E GARANTIAS FUNDAMENTAIS

POSSIBILIDADES DE AMPLIAÇÃO DOS DIREITOS E GARANTIAS FUNDAMENTAIS

FORMA DE ADMISSÃO DE DIREITOS E GARANTIAS FUNDAMENTAIS ADVINDOS DE LEGISLAÇÃO INTERNACIONAL

\section{SUBMISSÃO DO PAÍS A TRIBUNAL PENAL INTERNACIONAL AO} QUAL TENHA MANIFESTADO ADESÃO.

Assim, no primeiro nível da estrutura retórica do Título II, Capítulo I, da Constituição da República Federativa do Brasil, verifica-se uma porção central constituída pelo caput do artigo $5^{\circ}$. Esta se desdobra nos incisos, que a descrevem e detalham. Em seguida, os parágrafos tratam de diversas questões referentes à operacionalização do que foi afirmado nas seções anteriores.

A começar pelas orações independentes, ou seja, aquelas que não fazem parte de um complexo oracional, nos termos de Halliday (1985), cabe observar que há dois tipos de 
enumeração na parte do texto constitucional em estudo de cujo tratamento dependerá a identificação das orações independentes. Há um tipo de enumeração formada de incisos cujas afirmações constituem unidades informacionais distintas - umas em relação às outras e todas em relação à afirmação que as originou, colocada no caput do artigo. No outro tipo de enumeração, os incisos se desdobram em alíneas. Neste, as afirmações dispostas nas alíneas são parte integrante da proposição colocada no inciso que as originou. O quadro abaixo ilustra esta diferença. Como se pode verificar, não foram reproduzidos, no quadro, todos os 78 incisos que se seguem ao caput do artigo $5^{\circ}$, mas os dois primeiros deles, pois estes já mostram o diferente funcionamento desse tipo de enumeração — ou seja, aquele que se faz do caput do artigo para os incisos e aquele que se faz do inciso para as alíneas:

\section{TIPOS DE ENUMERAÇÕES}

\begin{tabular}{|c|c|}
\hline Do caput do artigo para os inciso & Do inciso para as alíneas \\
\hline $\begin{array}{l}\text { Art. } 5^{\circ} \text { Todos são iguais perante a lei, sem } \\
\text { distinção de qualquer natureza, garantindo-se aos } \\
\text { brasileiros e aos estrangeiros residentes no País a } \\
\text { inviolabilidade do direito à vida, à liberdade, à } \\
\text { igualdade, à Segurança e à propriedade, nos } \\
\text { termos seguintes: } \\
\text { I — homens e mulheres são iguais em direitos e } \\
\text { obrigações, nos termos desta Constituição; } \\
\text { II — ninguém será obrigado a fazer ou deixar de } \\
\text { fazer algum coisa senão em virtude de lei; }\end{array}$ & $\begin{array}{l}\text { XXVIII - são assegurados nos termos da lei: } \\
\text { a) a proteção às participações individuais em } \\
\text { obras coletivas e à reprodução da imagem e } \\
\text { voz humanas, inclusive nas atividades } \\
\text { desportivas; } \\
\text { b) o direito de fiscalização do aproveitamento } \\
\text { econômico das obras que criarem ou de que } \\
\text { participarem os criadores, aos intérpretes è às } \\
\text { respectivas representações sindicais e } \\
\text { associativas; }\end{array}$ \\
\hline
\end{tabular}

Assim, na enumeração do caput do artigo para os incisos, estes e o caput do artigo serão considerados períodos constituídos de orações — simples ou complexas, dependendo de cada caso - apesar dos sinais gráficos de pontuação que os separam (dois pontos e ponto-e-vírgula) não se prestarem a encerrar períodos, de acordo com a abordagem gramatical normativa do português. Na enumeração originada no caput do inciso em direção às alíneas, ambos serão considerados partes de um mesmo período também constituído de orações simples ou complexas, conforme o caso. Há uma única ocorrência do primeiro tipo de enumeração, pois a seção em estudo do texto constitucional contém apenas um artigo; por outro lado, há oito das enumerações do segundo tipo.

\section{Análise da macroestrutura retórica do art.5 da Carta Constitucional}

O conjunto dos 78 incisos funciona como um detalhamento dos direitos enunciados no caput do artigo ao qual sucede, de modo que um e outro podem ser tomados como porções textuais distintas que estabelecem entre si uma relação núcleo-satélite de elaboração, nos termos de Mathiessen e Thompson (1988). Nesta, a porção ancilar (o satélite formado pelos 78 incisos) 
traz informações adicionais àquelas apresentadas na porção nuclear (núcleo formado pelo caput do artigo). Em seguida, apresentam-se quatro parágrafos:

$\int 1^{\circ}$ As normas definidoras dos direitos e garantias fundamentais têm aplicação imediata.

$\int 2^{\circ}$ Os direitos e garantias expressos nesta Constituição não excluem outros decorrentes do regime e dos princípios por ela adotados, ou dos tratados internacionais em que a República Federativa do Brasil seja parte.

$\int 3^{\circ}$ Os tratados e convenções internacionais sobre direitos humanos que forem aprovados, em cada Casa do Congresso Nacional, em dois turnos, por três quintos dos votos dos respectivos membros, serão equivalentes às emendas constitucionais.

$\int 4^{\circ} \mathrm{O}$ Brasil se submete à jurisdição de Tribunal Penal Internacional a cuja criação tenha manifestado adesão.

O parágrafo primeiro, supracitado, mostra a forma de aplicabilidade dos incisos que constituem uma das porções textuais identificadas no primeiro nível da estrutura retórica do texto. Dessa forma, o parágrafo, ao apresentar o procedimento de aplicação do conjunto dos 78 incisos, estabelece com ele uma relação núcleo-satélite de meio.

Em seguida, o segundo parágrafo acrescenta uma informação nova em relação à porção textual constituída pelos incisos do artigo. O dispositivo afirma que os direitos e garantias expressos nos incisos podem ser ampliados pelo reconhecimento de direitos e garantias implícitos no próprios princípios constitucionais e por tratados ou convenções internacionais dos quais o País faça parte. Os direitos e garantias anteriormente expressos não constituem uma lista exaustiva, mas exemplificativa, podendo ser ampliados. Dessa forma, o segundo parágrafo estabelece com a porção textual constituída pelos incisos uma relação núcleo-satélite de elaboração, ao fornecer uma informação adicional — satélite — relacionada com o conteúdo dos incisos — que constituem o núcleo desta relação.

Uma vez admitida - como uma das possibilidades de ampliação de direitos e garantias expressos nos incisos - a adesão do Brasil a tratados e convenções internacionais, o terceiro parágrafo mostra o método de admissão de eventuais direitos humanos aprovados nessas instâncias. Ou seja, o terceiro parágrafo atua subsidiariamente em relação ao segundo, mostrando o procedimento pelo qual direitos que tenham origem no âmbito internacional possam se incorporar ao texto constitucional brasileiro. O dispositivo constitui, portanto, uma porção textual ancilar em relação à anterior, isto é, ao segundo parágrafo do artigo, o núcleo desta relação.

O quarto parágrafo finaliza o texto do artigo $5^{\circ}$ tratando - como o fazem os parágrafos segundo e terceiro - da interface entre os direitos e garantias fundamentais admitidos pelo texto constitucional brasileiro e os eventuais direitos humanos emergentes no âmbito internacional. 
Observa-se, mais uma vez, a adição de informação subsidiária em relação ao "já-dito" como estratégia de progressão textual. Assim, o quarto parágrafo estabelece com o segundo e o terceiro parágrafos uma relação núcleo-satélite de elaboração, ao acrescentar a informação relativa ao posicionamento do Brasil em relação à jurisdição de Tribunal Penal Internacional ao qual o País tenha manifestado adesão.

\section{Análise da articulação de orações no art. $5^{\circ}$ da Constituição}

O caput do art. $5^{\circ}$ é constituído de uma oração complexa. Nela, há duas orações que se articulam na ausência de conectivo, ou seja, por justaposição. Tal fenômeno se manifesta neste caso por uma estrutura em que a primeira oração apresenta-se na forma desenvolvida, isto é, com o verbo no Presente do Indicativo — forma finita — e a oração seguinte apresenta-se na forma reduzida de gerúndio. Embora o conectivo esteja ausente, a relação que se estabelece entre as orações é paratática aditiva, ou seja, a segunda oração adiciona à primeira uma nova informação, estabelecendo com ela uma relação de continuidade. Verifica-se também que a segunda oração especifica o sujeito da primeira — "Todos"—, ao caracterizá-lo como "brasileiros e estrangeiros residentes no País", o que delimita, ao território nacional, o âmbito de abrangência do direito à igualdade.

Art.5 Todos são iguais perante a lei, sem distinção de qualquer natureza, garantindose aos brasileiros e aos estrangeiros residentes no País a inviolabilidade do direito à vida, à liberdade, à igualdade, à segurança e à propriedade, nos termos seguintes:

São orações independentes os incisos: I, III, V, VII, IX, X, XIV, XXI, XXII, XXIII, XIV, XXX, XXXII, XXXIV, XXXV, XXXVI, XXXVII, XXXIX, XLI, XLII, XLIV, XLVII, XLVIII, XLIX, LII, LIII, LIV, LV, LVI, LVII, LVIII, LXIV, LXV, LXVII, LXX, LXXVI, LXXVII e o parágrafo primeiro. Embora não seja o objetivo deste trabalho analisar o interior das orações, mas as relações entre elas, determinados aspectos de suas organizações internas, por se mostrarem regulares, devem ser destacados. Grande parte das chamadas orações independentes utilizam o verbo "ser" seguido de predicativo do sujeito, variando a ordem em que as funções de "sujeito", "verbo" e "predicativo do sujeito" aparecem. Nos incisos I e III, por exemplo, o sujeito se antepõe ao verbo ao qual sucede o predicativo. Nestes casos, verifica-se que o sujeito é personificado; ou seja, o sujeito gramatical coincide com o "sujeito de direitos", um dos destinatários previstos pelo texto constitucional.

I - homens e mulheres são iguais em direitos e obrigações, nos termos desta Constituição;

III — ninguém será submetido a tortura nem a tratamento desumano ou degradante; 
Por outro lado, em incisos tais como V e VII, a oração independente começa com o verbo. Em seguida aparecem, nesta ordem: o predicativo do sujeito e o sujeito. Este, nesses casos como em outros, é constituído de um direito que se atribui aos cidadãos.

V — é assegurado o direito de resposta, proporcional ao agravo, além da indenização por dano material, moral ou à imagem;

VII — é assegurada, nos termos da lei, a prestação de assistência religiosa nas entidades civis e militares de internação coletiva;

Ainda no que se refere às orações independentes, um tipo de estrutura mencionado no início deste trabalho também exige uma análise interna, ainda que breve, pois revela um padrão que se repete em outras partes do texto constitucional. É a estrutura que se verifica no desdobramento do inciso em alíneas, conforme se observa em:

XLVII — não haverá penas:

a) de morte, salvo em caso de guerra declarada, nos termos do art. 84, XIX;

b) de caráter perpétuo;

c) de trabalhos forçados;

d) de banimento;

e) cruéis;

LXXVI — são gratuitos para os reconhecidamente pobres, na forma da lei:

a) o registro civil de nascimento;

b) a certidão de óbito;

Nos incisos supracitados, verifica-se que as alíneas integram sintaticamente o caput do inciso, embora não apareçam linearmente, ao lado do mesmo. As alíneas do inciso XLVII funcionam como adjuntos adnominais do termo "penas", pertencente ao caput. As alíneas do inciso LXXVI constituem o sujeito da oração disposta no caput. Verificam-se, então, estruturas de "encaixamento" - nestes casos, não, entre orações, mas entre as partes constituintes da oração. Em ambos os casos, as alíneas são parte integrante dos caputs de seus respectivos incisos.

Quanto às orações independentes, verifica-se também a existência de estruturas contendo duas unidades informacionais, embora apresentem um único núcleo verbal explícito:

$\mathrm{X}$ — são invioláveis a intimidade, a vida privada, a honra e a imagem das pessoas, assegurado o direito a indenização pelo dano material ou moral decorrente de sua violação;

$\mathrm{XIV}$ - é assegurado a todos o acesso à informação e resguardado o sigilo da fonte, quando necessário ao exercício profissional;

XVII — é plena a liberdade de associação para fins lícitos, vedada a de caráter paramilitar;

Nos incisos acima, verifica-se uma estrutura do tipo: 
Unidade informacional construída com o verbo na forma desenvolvida + Unidade
informacional iniciada com um predicativo do sujeito (com o verbo ser implícito)

A unidade informacional iniciada com um predicativo do sujeito mantém com a anterior uma relação de continuidade. Verifica-se entre tais unidades informacionais uma relação de lista, pois cada uma delas é um núcleo distinto, sendo, portanto, coordenadas entre si, conforme se pode verificar, por exemplo, no inciso $\mathrm{X}$ :

são invioláveis a intimidade, a vida

privada, a honra e a imagem das pessoas, assegurado o direito a indenização pelo dano material ou moral decorrente de sua violação

Orações que se constróem em torno do verbo ser são freqüentes não só nos incisos que se constituem de orações independentes como também naqueles que se constituem de complexos oracionais. Esse tipo de estrutura está presente também no caput do artigo, mas, ausente, nos parágrafos.

Conforme mencionado, o parágrafo primeiro constitui uma oração independente, que não apresenta um comportamento sintático muito diferente daquele observado em diversos incisos que também constituem um período simples, exceto pelo fato de que retoma anaforicamente tudo o que foi dito no caput do artigo e nos 78 incisos e cataforicamente ao que se segue nos parágrafos posteriores. O parágrafo primeiro é o dispositivo que contém a forma de aplicabilidade de todo o conteúdo do artigo, referindo-se diretamente à instância enunciativa, ou seja, ao momento de execução da lei.

$\mathrm{Na}$ identificação de complexos oracionais, verificam-se também estruturas regulares que definem determinados padrões de organização. Alguns dispositivos do artigo $5^{\circ}$ apresentam uma oração complexa constituída de dois núcleos verbais, na qual a primeira unidade informacional é expandida pela segunda pelo acréscimo de informação que especifica a primeira afirmação, mais genérica. No interior do complexo, a segunda oração — na forma reduzida de gerúndio — se articula com a primeira, configurada na forma desenvolvida. Neste tipo de relação, que se dá sem a presença de um conectivo, nenhum membro é subordinado a outro; trata-se de uma relação paratática. É o que se verifica, por exemplo, nos incisos:

IV — é livre a manifestação do pensamento, sendo vedado o anonimato;

VI - é inviolável a liberdade de consciência e de crença, sendo assegurado o livre exercício dos cultos religiosos e garantida, na forma da lei, a proteção aos locais e suas liturgias;

XVIII - a criação de associações e, na forma da lei, a de cooperativas independem de autorização, sendo vedada a interferência estatal em seu funcionamento; 
Nos dispositivos supracitados, percebe-se uma relação paratática entre as orações do complexo, porém, enquanto nos incisos VI e XVIII se verifica uma relação aditiva, no inciso IV, é possível inferir também uma relação opositiva entre a liberdade de manifestação do pensamento enunciada pela primeira unidade informacional e a proibição do anonimato, enunciada na segunda unidade.

Ao contrário das construções paratáticas aditivas, bastante freqüentes na seção do texto constitucional em estudo, as construções hipotáticas adverbiais, apresentam, muitas vezes, o conectivo que explicita a relação interoracional. É o que se verifica na identificação de algumas orações hipotáticas adverbiais condicionais, temporais e finais, conforme se observa nos incisos seguintes:

XXV — no caso de iminente perigo público, a autoridade competente poderá usar de propriedade particular, assegurada ao proprietário indenização ulterior, se houver dano;

XXXI — a sucessão de bens de estrangeiros situados no País será regulada pela lei brasileira em benefício do cônjuge ou dos filhos brasileiros, sempre que não lhes seja mais favorável a lei pessoal do "de cujus";

L — às presidiárias serão asseguradas condições para que possam permanecer com seus filhos durante o período de amamentação;

LIX — será admitida ação privada nos crimes de ação pública, se esta não for intentada no prazo legal;

LX - a lei só poderá restringir a publicidade dos atos processuais quando a defesa da intimidade ou o interesse social o exigirem;

LXVI — ninguém será levado à prisão ou nela mantido, quando a lei admitir a liberdade provisória, com ou sem fiança;

LXXI - conceder-se-á mandado de injunção sempre que a falta de norma regulamentadora torne inviável o exercício dos direitos e liberdades constitucionais e das prerrogativas inerentes à nacionalidade, à soberania e à cidadania;

LXXII — conceder-se-á "habeas-data":

a) para assegurar o conhecimento de informações relativas à pessoa do impetrante, constantes de registros ou bancos de dados de entidades governamentais ou de caráter público;

b) para a retificação de dados, Quando não se prefira fazê-lo por processo sigiloso, judicial ou administrativo;

(Grifos da autora)

Como se verifica acima, as orações hipotáticas adverbiais condicionais podem expressar, simultaneamente, idéia de condição e de tempo. É o que ocorre, por exemplo, nos incisos XXXI 
e LXXI, nos quais a segunda oração do complexo — iniciada por conectivo — enuncia o momento em que se concederá um determinado direito enunciado pela primeira oração. Essa delimitação temporal é também a condição para que se cumpra o direito expresso nos respectivos incisos. As orações hipotáticas adverbiais temporais iniciadas com o advérbio "quando" conectivo tipicamente temporal — também podem ser vistas sob esse prisma ambivalente, isto é, expressam, simultaneamente uma delimitação temporal e uma condição, para que o direito enunciado pela primeira oração se realize.

Quanto às orações hipotáticas adverbiais finais, verificam-se duas configurações distintas. No inciso L, a segunda oração do complexo especifica a finalidade de um direito apenas vagamente enunciado pela primeira: o direito assegurado às presidiárias de "ter condições". Já o inciso LXXII apresenta um tipo de organização comentado na seção 1.1 deste trabalho: uma enumeração que se faz do caput do inciso para as alíneas. Estas apresentam a finalidade da concessão de habeas data, direito enunciado pelo inciso. A alínea "a)" é constituída por uma oração hipotática adverbial final cujo núcleo verbal se apresenta na forma infinita, com o verbo no infinitivo. A alínea “b)", entretanto, não é formada apenas de uma única oração. Ela se inicia com a nominalização do verbo "retificar" seguido de uma restrição temporal constituída de um complexo de orações encaixadas. Há basicamente na alínea " $b$ )" duas unidades informacionais: a finalidade do direito enunciado pelo inciso e a condição para fazê-lo. Trata-se de uma espécie de “condição negativa", pois expressa uma ausência de preferência pelo cidadão por outro modo de retificação de dados igualmente assegurado pela Constituição: o modo sigiloso.

Finalmente, na identificação de complexos oracionais, verificam-se diversas estruturas de encaixamento tanto nos incisos quanto nos parágrafos, sendo bastante comum a ocorrência de orações adjetivas restritivas, como nos exemplos seguintes:

XII — é inviolável o sigilo da correspondência e das comunicações telegráficas, de dados e das comunicações telefônicas, salvo, no último caso, por ordem judicial, nas hipóteses e na forma que a lei estabelecer para fins de investigação criminal ou instrução processual penal;

XXXIII — todos têm direito a receber dos órgãos públicos informações de seu interesse particular, ou de interesse coletivo ou geral, que serão prestadas no prazo da lei, sob pena de responsabilidade, ressalvadas aquelas cujo sigilo seja imprescindível à segurança da sociedade e do Estado;

LXXIV — o Estado prestará assistência jurídica integral e gratuita aos que comprovarem insuficiência de recursos;

LXXV — o Estado indenizará o condenado por erro judiciário, assim como o que ficar preso além do tempo fixado na sentença; 
LXXVIII — a todos, no âmbito judicial e administrativo, são assegurados a razoável duração do processo e os meios que garantam a celeridade de sua tramitação.

$\int 3^{\circ}$ Os tratados e convenções internacionais sobre direitos humanos que forem aprovados, em cada Casa do Congresso Nacional, em dois turnos, por três quintos dos votos dos respectivos membros, serão equivalentes às emendas constitucionais.

$\int 4^{\circ} \mathrm{O}$ Brasil se submete à jurisdição de Tribunal Penal Internacional a cuja criação tenha manifestado adesão.

(Grifos da autora)

Conforme se observa nos dispositivos constitucionais reproduzidos acima, as orações adjetivas restritivas cumprem um papel fundamental no texto constitucional cujo objetivo entre outros é o de normatizar relações sociais: especificar, delimitar um termo antecedente fazendo com que os comandos do texto produzam os efeitos jurídicos por ele previstos na realidade fática. As delimitações, especificações e restrições presentes no texto constitucional contribuem para que a norma atinja os sujeitos de direitos na proporção e nas situações específicas. É importante lembrar que o texto legal, inclusive o constitucional, prevê, pelo menos, dois destinatários: o cidadão comum e o operador do direito. A este último, não basta uma afirmação genérica sobre direitos, obrigações e/ou proibições; é preciso que se especifiquem cuidadosamente os aspectos que tais direitos, obrigações e/ou proibições envolvem.

Até o momento, foram focalizados complexos oracionais compostos de até duas orações. Entretanto, observam-se outros complexos mais densos, compostos de três ou mais núcleos verbais, apresentando diversas relações tanto paratáticas quanto hipotáticas, além de estruturas de encaixamento.

XIX - as associações só poderão ser compulsoriamente dissolvidas ou ter suas atividades suspensas por decisão judicial, exigindo-se, no primeiro caso, o trânsito em julgado;

XXVI - a pequena propriedade rural, assim definida em lei, desde que trabalhada pela família, não será objeto de penhora para pagamento de débitos decorrentes de sua atividade produtiva, dispondo a lei sobre os meios de financiar o seu desenvolvimento;

LXXIII - qualquer cidadão é parte legítima para propor ação popular que vise a anular ato lesivo ao patrimônio público ou de entidade de que o Estado participe, à moralidade administrativa, ao meio ambiente e ao patrimônio histórico e cultural, ficando o autor, salvo comprovada má-fé, isento de custas judiciais e do ônus da sucumbência;

(Grifos da autora)

A princípio, a diversificada apresentação dos complexos oracionais mais densos, de três ou mais orações, parece não oferecer parâmetros de generalização. No inciso XIX, as três 
orações relacionam-se paraticamente. A segunda inicia-se com o conector “ou”, neste caso, inclusivo; a segunda oração apresenta uma alternativa além daquela estabelecida pela primeira. A terceira oração, com o verbo no gerúndio, adiciona uma informação nova ao que foi exposto nas duas anteriores. Já no incisos XXVI e LXXIII, aparecem relações interoracionais não só paratáticas, como também hipotáticas, além estruturas de encaixamento. No inciso LXXIII, por exemplo, a segunda oração estabelece com a primeira uma relação adverbial de finalidade, a chamada hipotaxe de realce, nos termos de Halliday (1985). A terceira oração apresenta uma restrição a um sintagma nominal da oração anterior: ação popular, trata-se de uma estrutura de encaixamento à qual sucede um outra de tipo semelhante, estabelecida pela quarta oração. Esta é parte integrante da anterior, funcionando como objeto indireto exigido pela estrutura argumental do verbo visar. A quinta oração também é uma estrutura encaixada na anterior, funcionando como uma adjetiva restritiva em relação a ela. A sexta oração relaciona-se com as anteriores, parataticamente, adicionando uma nova informação.

\section{Considerações finais}

Buscou-se verificar neste trabalho como se organizam as afirmações distribuídas nas partes do texto legal, especificamente no texto constitucional e, dentro delas, como se articulam as orações. $\mathrm{Na}$ macroestrutura retórica do texto, verificou-se que o conjunto dos incisos, ao apresentar detalhamento de informação apresentada no caput do artigo, forma uma porção textual a ele submetida. O caput do artigo também condiciona a organização das informações nos parágrafos. Estes, entretanto, não constituem uma única porção textual, pois há entre eles um maior grau de autonomia, tendo em vista que cada parágrafo apresenta uma unidade temática distinta, embora todas subordinadas ao caput do artigo. Cada parágrafo trata de um aspecto que diz respeito ora à ampliação dos direitos citados no caput do artigo e detalhados nos incisos, ora à forma de aplicação desses direitos, ora à forma de admissão de direitos provindos de legislação internacional. O parágrafo segundo faz uma retomada, que não se restringe ao âmbito do Título II, no qual está inserido, mas ao Título I "Dos Princípios Fundamentais" e a todo o texto constitucional ao afirmar que os direitos e garantias nele expressos "não excluem outros decorrentes do regime e dos princípios por ela adotados".

Quanto à articulação de orações, verificou-se a ausência de conectivos em muitos complexos oracionais, geralmente organizados por relações paratáticas de adição. A progressão textual se dá freqüentemente pela apresentação de informações que se mostram como núcleos distintos organizados numa relação de lista, ou seja, cada oração é uma unidade informacional distinta, não havendo dominância de uma sobre a outra. Nos complexos oracionais nos quais se observam orações hipotáticas adverbiais, os elos conectivos são explícitos, ocorrendo a 
sobreposição de relações da causa e de tempo no mesmo complexo. Na parte do texto constitucional em estudo, a oração adverbial apresentou-se posposta à principal.

Embora os complexos oracionais nos quais se verificam orações adjetivas restritivas sejam vistos como estruturas de encaixamento, e não como fenômeno de articulação de orações, esse tipo de complexo é bastante freqüente no Título II do texto constitucional. Esta ocorrência cumpre um dos objetivos comunicativos do texto legal: o de precisar, especificar tanto quanto possível as regras nele prescritas.

Ainda no que diz respeito à articulação de orações, verificou-se o aparecimento de alguns complexos oracionais densos, compostos de até quatro núcleos verbais. Neles, as relações interoracionais diversificam-se entre paratáticas e hipotáticas, apresentando também estruturas de encaixamanto.

Tanto na análise da macroestrutura retórica do texto constitucional quanto na identificação das relações oracionais, cada unidade do texto constitucional: o caput do artigo, os parágrafos, os incisos e até mesmo as alíneas - que apresentam um grau de dependência maior da unidade à qual estão imediatamente subordinadas - mostram um elevado grau de conclusibilidade. Do observado, o empacotamento das informações no texto constitucional sofre o impacto da dinâmica prescrita pela técnica legislativa, a qual recomenda que se abram novos artigos, parágrafos, incisos e alíneas para que não se acumulem informações em uma única parte constituinte do texto.

\section{Referências Bibliográficas}

BECHARA, Evanildo. Moderna Gramática portuguesa. 37 ed. Rio de Janeiro: LUCERNA, 2002.

BRASIL. CONSTITUiÇÃo (1988) CONSTITUiÇÃO DA REPÚBLICA FEDERATIVA DO BRASIL, 1988. BRASÍlIA: SENADO FEDERAL, CENTRO GRÁFICO, 1988. 292P.

CARVAlHO, Kildare. G. TÉCnicA Legislativa. 3.eD. ReV., Atual. E Ampl. Belo HORIZONTE: DEL REY, 2003.

DECAT, MARIA BeATriz NASCIMENTO. "LeITE COM MANGA MORRE!”: DA HIPOTAXE ADVERBLAL NO PORTUGUÊS EM USO. TESE DE DOUTORADO. PUC-SP, 1993. (INÉDITA)

HALLIDAY, M. A. K. “AN INTRODUCTION TO FUNCTIONAL GRAMMAR”. LONDON:EDWARD ARNOLD PUBLISHERS LTD, 1985.

MANN, W. C., THOMPSON, S. A. RELATIONAL PROPOSITIONS IN DISCOURSE. ISI/RR - 83-115, 1983.

KOCH, Ingedore VillaçA. A INTER-AÇÃo PEL A Linguagem. 9 ed. SÃo Paulo: Contexto, 2004. 